Check for updates

Cite this: RSC Adv., 2017, 7, 53622

\title{
The recycle of red mud as excellent SCR catalyst for removal of $\mathrm{NO}_{x}^{\dagger}$
}

\author{
Changming Li, ${ }^{a}$ Hong Zeng, ${ }^{\text {ab }}$ Pingle Liu, ${ }^{b}$ Jian Yu, (D) *a Feng Guo, ${ }^{a}$ Guangwen Xu (D) ac \\ and Zhan-guo Zhang ${ }^{d}$
}

The development of new routes for the utilization of red mud (RM) waste is very urgent due to its huge accumulation and potential environmental harm. By taking advantage of its $\mathrm{Fe}-\mathrm{Al}-\mathrm{Si}-\mathrm{Ti}$ composition and excellent plasticity, we developed a ball milling and acid-base neutralization method to reuse the RM waste as Fe-based denitration catalysts. The resulting RM catalysts demonstrate excellent catalytic activity and stability with $>90 \% \mathrm{NO}$ conversion above $400{ }^{\circ} \mathrm{C}$ in the presence of $\mathrm{SO}_{2}$ and $\mathrm{H}_{2} \mathrm{O}$, which is even much better than that of a commercial $\mathrm{V}-\mathrm{W}-\mathrm{Ti}$ catalyst. Characterization data reveal that our treatment eliminates poisonous alkaline metal elements and increases dispersion of RM particles, making the RM active for denitration reactions. The formation of ferric sulfate species with more reducible $\mathrm{Fe}^{3+} / \mathrm{Fe}^{2+}$ active sites by a $\mathrm{SO}_{2}$ activation method can further enhance the denitration activity. Moreover, $\mathrm{NH}_{3}-\mathrm{TPD}$ and in situ IR results demonstrate that the $\mathrm{NH}_{3}-\mathrm{SCR}$ reaction over the $\mathrm{RM}$ catalyst follows the Eley-Rideal mechanism at high temperature and the increased absorption of $\mathrm{NH}_{3}$ for alkaline metal-eliminated or $\mathrm{SO}_{2}$-activated samples accounts for its high $\mathrm{DeNO}_{x}$ efficiency. The demonstrated feasibility for reusage of the RM as $\mathrm{DeNO}_{x}$ catalyst has promising industrial prospects for its extremely low cost, no toxicity, and high efficiency.

Received 18th September 2017
Accepted 31st October 2017

DOI: $10.1039 / c 7 r a 10348 d$

rsc.li/rsc-advances up $10 \%$ of the total amount up to now. Therefore, it is very urgent to develop new routes for the utilization of RM with innovative technologies.

Selective catalytic reduction (SCR) of nitrogen oxides $\left(\mathrm{NO}_{x}\right)$ is one of the most effective technologies to reduce $\mathrm{NO}_{x}$ emission from industrial flue gas, in which $\mathrm{DeNO}_{x}$ catalysts play a key role to achieve good DeNO $_{x}$ performance as well as low investment costs. Although commercial V-based catalysts have achieved great success in the temperature range of $320-400{ }^{\circ} \mathrm{C}$, their high price, toxicity, and sublimation of $\mathrm{VO}_{x}$ still restrict their industrial applications. ${ }^{6}$ Meanwhile, $\mathrm{V}_{2} \mathrm{O}_{5} / \mathrm{TiO}_{2}$ catalysts could not be applied at high temperatures, especially as temperatures of flue gas exceeding $400{ }^{\circ} \mathrm{C}$ result in sintering and deactivation of the catalyst. Alternatively, Fe-based catalysts have recently aroused intense research interests owing to their low cost and non-toxicity, especially high $\mathrm{DeNO}_{x}$ activity in a high temperature range. ${ }^{7,8}$

Considering the composition and good plasticity of RM, our idea is to explore the reuse of the RM waste as a Fe-based denitration catalyst. In China, the demand for SCR catalyst exceeds $4 \times 10^{4} \mathrm{~m}^{3} / \mathrm{a}$, which will provide an effective way to utilize the RM. ${ }^{9}$ The proposed technical route will possess great advantage in terms of its very low cost, non-toxicity, and good activity at high temperatures. However, the high alkali metal content, low specific surface, and serious agglomeration of hematite will cause great difficulty if using $\mathrm{RM}$ as a $\mathrm{DeNO}_{x}$ catalyst directly, which will still be a challenging work.
${ }^{a}$ State Key Laboratory of Multi-phase Complex Systems, Institute of Process Engineering, Chinese Academy of Sciences, Beijing 100190, China. E-mail: yujian@ ipe.ac.cn

${ }^{b}$ School of Chemical Engineering, Xiangtan University, Xiangtan, Hunan 411105, PR China

'Institute of Industrial Chemistry and Energy Technology, Shenyang University of Chemical Technology, Shenyang 110142, China

${ }^{d}$ National Institute of Advanced Industrial Science and Technology (AIST), 16-1 Onogawa, Tsukuba, 305-8569 Ibaraki, Japan

$\dagger$ Electronic supplementary information (ESI) available. See DOI: $10.1039 / \mathrm{c} 7 \mathrm{ra} 10348 \mathrm{~d}$ 
In this work, RM-based catalysts were obtained by a simple ball milling and acid-base neutralization method; they exhibit comparable catalytic performance with commercial $\mathrm{V}-\mathrm{W}-\mathrm{Ti}$ catalyst at high temperatures. Multiple characterizations (XRF, XRD, SEM, TEM, BET) were performed to analyze composition and structure transformations from RM waste to RM-based catalysts. Furthermore, TG, XPS, $\mathrm{H}_{2}$-TPD, $\mathrm{NH}_{3}$-TPD and in situ FT-IR were executed to reveal structural features and adsorption/reaction behaviors of active sites for RM-based catalysts. This work will demonstrate feasibility for the reusage of RM waste as an efficient DeNO$_{x}$ catalyst at high temperatures.

\section{Experiments}

\subsection{Materials}

Raw RM was collected from Shandong Aluminum Industry Company, China and it exhibits strong alkalinity $(\mathrm{pH}=12-14)$ due to the existence of sodium oxide in it. The sample was dried and ground for further utilization. The supports of $\mathrm{SiO}_{2}, \mathrm{Al}_{2} \mathrm{O}_{3}$, and $\mathrm{TiO}_{2}$ are from Aladdin with specific surface areas of 250, 198 , and $55 \mathrm{~m}^{2} \mathrm{~g}^{-1}$, respectively. Other chemicals including ferric nitrate, ammonium metavanadate, ammonium metatungstate, $\mathrm{HNO}_{3}, \mathrm{NaOH}$, and deionized water were of reagent grade and used without any pretreatment.

Additionally, commercial V-W-Ti catalyst (denoted as DF) from Chengdu Dongfang KWH Environmental Protection Catalyst Co., Ltd (China) was used as a reference sample. Prior to $\mathrm{DeNO}_{x}$ evaluation, this monolithic honeycomb catalyst was cut and crushed into powder.

\subsection{Synthesis of catalysts}

Fig. 1 shows the route for synthesis of RM-based catalysts by the ball milling and acid-base neutralization method. First, RM was digested with $20 \mathrm{wt} \% \mathrm{HNO}_{3}$ aqueous $\left(\mathrm{HNO}_{3} / \mathrm{RM}=0.5,1,2\right.$, 3) in a ball mill for $6 \mathrm{~h}$; then the resulting slurry was aged overnight. Second, the slurry was neutralized by adding $\mathrm{NaOH}$

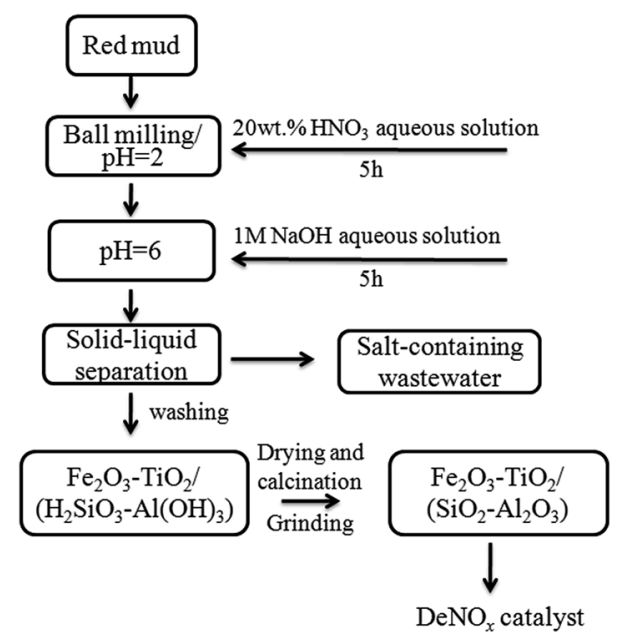

Fig. 1 Schematic diagram for preparation of the RM-based catalyst by the ball milling and acid-base neutralization method. aqueous solution dropwise under stirring until the $\mathrm{pH}$ increased to 6; the slurry was washed several times with distilled water to remove residual $\mathrm{Na}, \mathrm{K}, \mathrm{Ca}$, and $\mathrm{Mg}$ to form $\mathrm{Fe}_{2} \mathrm{O}_{3}-\mathrm{TiO}_{2} /$ $\left(\mathrm{H}_{2} \mathrm{SiO}_{3}-\mathrm{Al}(\mathrm{OH})_{3}\right)$ precipitate. Lastly, the obtained filter cake was dried for $10 \mathrm{~h}$ at $120{ }^{\circ} \mathrm{C}$, and calcined for $3 \mathrm{~h}$ at $500-600{ }^{\circ} \mathrm{C}$ to obtain RM-based catalysts.

The supported $\mathrm{Fe}_{2} \mathrm{O}_{3}$ catalysts on different supports $\left(\mathrm{SiO}_{2}\right.$, $\mathrm{Al}_{2} \mathrm{O}_{3}, \mathrm{TiO}_{2}$, and their physical mixtures) were prepared by the conventional incipient wetness impregnation method using ferric nitrate as an iron source. Moreover, the VWTi catalyst without inactive additives was prepared by mixing ammonium metavanadate, ammonium metatungstate, and $\mathrm{TiO}_{2}$ powder with $30 \mathrm{wt} \%$ water to form a uniform sludge. All samples were dried for $10 \mathrm{~h}$ at $120^{\circ} \mathrm{C}$, and calcined for $3 \mathrm{~h}$ at $550{ }^{\circ} \mathrm{C}$ to obtain corresponding catalysts.

\subsection{Catalytic test}

Catalytic activity measurements for SCR of $\mathrm{NO}$ by $\mathrm{NH}_{3}$ were conducted in a quartz fixed bed reactor of $11.5 \mathrm{~mm}$ in internal diameter under atmospheric pressure. In the present work, the tested catalyst was crushed with particle sizes of $0.3-0.4 \mathrm{~mm}$. The feed gas consisted of $500 \mathrm{ppm} \mathrm{NO}, 500 \mathrm{ppm} \mathrm{NH}_{3}, 500 \mathrm{ppm}$ $\mathrm{SO}_{2}, 5 \% \mathrm{O}_{2}$, and 10 vol\% $\mathrm{H}_{2} \mathrm{O}$ balanced with $\mathrm{N}_{2}$. The total flow rate through the reactor was kept at $6 \mathrm{~L} \mathrm{~min}^{-1}$ (STP) to give a Gas Hourly Space Velocity (GHSV) of $60000 \mathrm{~h}^{-1}$. Measurements were performed at fixed temperatures per $50{ }^{\circ} \mathrm{C}$ from 300 to $450{ }^{\circ} \mathrm{C}$ and kept for $60 \mathrm{~min}$ at each stage. Feed and product concentrations were continually monitored using a Horiba PG250 on-line flue gas analyzer (Horiba, Kyoto, Japan). The NO conversion was calculated according to measured inlet and outlet NO concentrations.

\subsection{Sample characterization}

Chemical compositions of RM-based samples were determined with an Axios X-ray fluorescence (XRF) spectrometer (PANalytical X'pert, Almelo, Netherlands). Their X-ray diffraction (XRD) patterns were obtained in the range of $2 \theta$ from $10^{\circ}$ to $90^{\circ}$ on a D/Max-RB diffractometer (Rigaku Corp., Tokyo, Japan) with $\mathrm{Cu} \mathrm{K} \alpha$ radiation. Nitrogen adsorption/desorption isotherms were recorded on an ASAP 2020 (Micromeritics Instrument Corp., Norcross, USA) at $77 \mathrm{~K}$. The Brunauer-Emmett-Teller (BET) equation was used to calculate the specific surface area $\left(S_{\mathrm{BET}}\right)$, and pore size distributions were calculated from the adsorption branch using the Barret-Joyner-Halenda (BJH) model. Composition and oxidation states of the elements were recorded by X-ray photoelectron spectroscopy (XPS) with an ESCALAB 250Xi electron spectrometer from Thermo Fisher Scientific Corp. (New York, USA). Reported binding energy values were all corrected by referring to the binding energy of $\mathrm{C}$ 1s, that is, $284.8 \mathrm{eV}$. Morphology of RM-based samples was observed using JSM-7001F scanning electron microscopy (SEM, JEOL Ltd., Tokyo, Japan) at an accelerating voltage of $10 \mathrm{kV}$, and JEM-2100 of JEOL transmission electron microscope (TEM) at $200 \mathrm{kV}$, respectively. Formation of surface sulfate species was investigated by thermogravimetry (TG) measurements that were carried out on an Exstar TG/DTA 7300 (Seiko Instrument Inc., 
Tokyo, Japan) under argon atmosphere and a heating rate of $20{ }^{\circ} \mathrm{C} \min ^{-1}$ from $30{ }^{\circ} \mathrm{C}$ to $1000{ }^{\circ} \mathrm{C}$.

$\mathrm{NH}_{3}$-TPD and $\mathrm{H}_{2}$-TPR experiments were performed on an AutoChem II-2920s V5.02 from Micromeritics Instrument Corp. (Norcross, USA). First, $0.1 \mathrm{~g}$ of sample was loaded in a quartz Utube and heated from room temperature to $300{ }^{\circ} \mathrm{C}$ at $10{ }^{\circ} \mathrm{C} \mathrm{min}{ }^{-1}$, maintained for $60 \mathrm{~min}$ in helium atmosphere, and cooled to room temperature. After pre-absorption of $10 \mathrm{vol} \%$ $\mathrm{NH}_{3}$ for $60 \mathrm{~min}$ and purging with $\mathrm{He}$ for $30 \mathrm{~min}$ at room temperature, the $\mathrm{NH}_{3}$-TPD test was performed by heating the samples to $750{ }^{\circ} \mathrm{C}$ at $10{ }^{\circ} \mathrm{C} \mathrm{min}^{-1}$ in He atmosphere. For the $\mathrm{H}_{2}$ TPR test, the pre-processing sample was heated to $1000{ }^{\circ} \mathrm{C}$ at $10{ }^{\circ} \mathrm{C} \mathrm{min}{ }^{-1}$ in 10 vol\% $\mathrm{H}_{2}$ atmosphere. Released $\mathrm{NH}_{3}$ and $\mathrm{H}_{2}$ were detected continuously by a TCD detector. All the flow rates

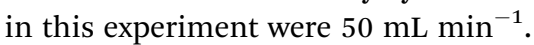

In situ DRIFTS experiments were performed on a FTIR spectrometer (Bruker, Tensor 27) equipped with a Harrick DRIFT cell containing $\mathrm{ZnSe} / \mathrm{KBr}$ windows and a MCT detector. Prior to each experiment, the sample was pre-treated at $500{ }^{\circ} \mathrm{C}$ for $1 \mathrm{~h}$ in a flow of nitrogen. The background spectrum was collected in flowing nitrogen at 30, 100, 200, 300, 350, and $400{ }^{\circ} \mathrm{C}$, respectively. For the desorption test, the sample was exposed in the flow of $\mathrm{NH}_{3}$ (or $\mathrm{NO}+\mathrm{O}_{2}$ ) for 20 min, purged by nitrogen for $40 \mathrm{~min}$ at $30{ }^{\circ} \mathrm{C}$, and then heated to the target temperature of $30,100,200,300,350$, and $400{ }^{\circ} \mathrm{C}$ for $20 \mathrm{~min}$ to record the spectrum, respectively. In the transient studies, the catalyst was first pre-exposed to a flow of $\mathrm{NH}_{3}$ (or $\mathrm{NO}+\mathrm{O}_{2}$ ) for $20 \mathrm{~min}$, then purged with nitrogen for $40 \mathrm{~min}$ at $350{ }^{\circ} \mathrm{C}$, subsequently in the flow of $\mathrm{NO}+\mathrm{O}_{2}\left(\right.$ or $\left.\mathrm{NH}_{3}\right)$ to get the time dependent changes of the DRIFT spectra. All IR spectra were obtained by collecting 50 scans with a resolution of $4 \mathrm{~cm}^{-1}$.

\section{Results and discussion}

\subsection{The performance of RM-based catalysts}

Fig. 2 displays the $\mathrm{NH}_{3}$-SCR performance of RM-based catalysts after different treatments. It can be observed from Fig. $2 \mathrm{~A}$ that
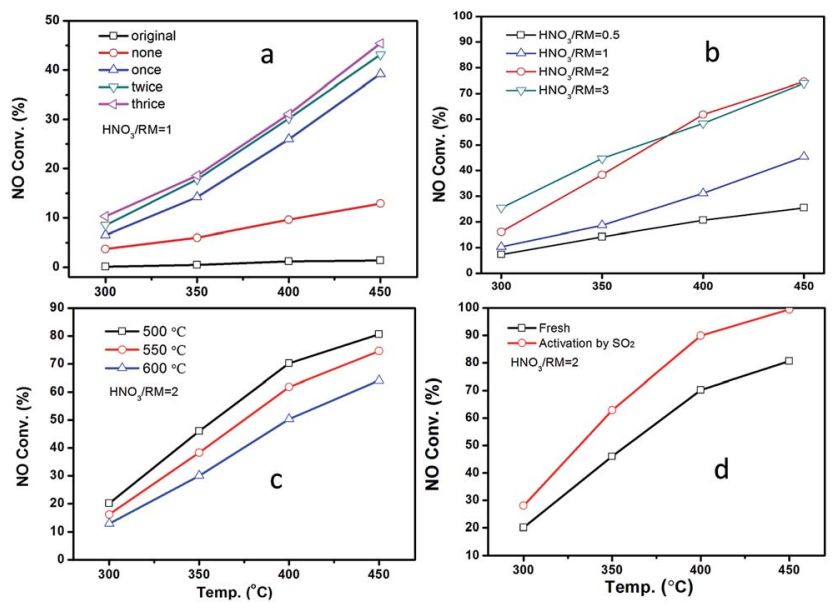

Fig. 2 The performance of RM-based catalysts with different treated methods: (a) treated by different washing times, (b) treated by different ratios of $\mathrm{HNO}_{3} / \mathrm{RM}$, (c) treated by different calcination temperatures, and (d) activation by $\mathrm{SO}_{2}$. The ratio of $\mathrm{NH}_{3} / \mathrm{NO}$ was 1 . the original $\mathrm{RM}$ sample shows nearly no denitration activity even at $450{ }^{\circ} \mathrm{C}$. After being treated by $\mathrm{HNO}_{3}$ with a $\mathrm{HNO}_{3} / \mathrm{RM}$ ratio of 1 , the $\mathrm{RM}$ sample becomes active for the $\mathrm{NH}_{3}$-SCR reaction with above $45 \%$ NO conversion. Increased washing times can promote catalytic activity. The close activity curves for the washed-twice/thrice samples indicate that washing two times will be enough to remove the poisonous elements to a level useful for the SCR reaction. The optimization of $\mathrm{HNO}_{3} /$ $\mathrm{RM}$ ratio was also investigated in our work. As shown in Fig. 2B, an increase of $\mathrm{HNO}_{3} / \mathrm{RM}$ ratio to 2 can notably improve the catalytic activity with a $75 \% \mathrm{NO}$ conversion at $450{ }^{\circ} \mathrm{C}$, but the increase of $\mathrm{HNO}_{3} / \mathrm{RM}$ ratio to 3 only exerts a slight promotion effect for $\mathrm{DeNO}_{x}$ activity at low temperature. The study of calcination temperature for the treated RM sample (Fig. 2C) manifests that catalytic activity increases with reduced calcination temperature and the sample calcinated at $500{ }^{\circ} \mathrm{C}$ has the best activity with $80 \%$ NO conversion. Most remarkably, it can be found that the activation of $\mathrm{RM}$ catalyst by $\mathrm{SO}_{2}$ can significantly improve the NO conversion close to $100 \%$ above $400{ }^{\circ} \mathrm{C}$ (Fig. 2D). In addition, $\mathrm{N}_{2} \mathrm{O}$ was also detected during the catalytic test as shown in Fig. S1.† It can be seen that the increased washing times, high ratio of $\mathrm{HNO}_{3} / \mathrm{RM}$, and low calcination temperature can lower the generation of $\mathrm{N}_{2} \mathrm{O}$ and increase $\mathrm{DeNO}_{x}$ selectivity. In brief, by treating the original RM waste through nitric acid digestion, washing, and activation processes, the RM waste can be used as a low cost and effective denitration catalyst at high temperature.

As a comparison, the DeNO$_{x}$ performances of supported $\mathrm{Fe}_{2} \mathrm{O}_{3}$ catalysts on different supports $\left(\mathrm{SiO}_{2}, \mathrm{Al}_{2} \mathrm{O}_{3}, \mathrm{TiO}_{2}\right.$, and their physical mixture) are shown in Fig. S2A. $\dagger$ It can be seen that the activity follows the order of $\mathrm{Fe}_{2} \mathrm{O}_{3} / \mathrm{SiO}_{2}<\mathrm{Fe}_{2} \mathrm{O}_{3} / \mathrm{Al}_{2} \mathrm{O}_{3}<$ $\mathrm{Fe}_{2} \mathrm{O}_{3} / \mathrm{SiO}_{2}-\mathrm{Al}_{2} \mathrm{O}_{3}-\mathrm{TiO}_{2}<\mathrm{Fe}_{2} \mathrm{O}_{3} / \mathrm{TiO}_{2}$, indicating the merit of the composite support. However, the activity of RM catalysts is even comparable with the $\mathrm{Fe}_{2} \mathrm{O}_{3} / \mathrm{TiO}_{2}$ catalyst, which may result from the homogeneity of composite oxides in chemical levels.

In real flue gas, high contents of $\mathrm{SO}_{2}$ and $\mathrm{H}_{2} \mathrm{O}$ may have a great effect on the catalytic activity. The impact of $\mathrm{SO}_{2}$ and $\mathrm{H}_{2} \mathrm{O}$ was studied as shown in Fig. 3. The introduction of $\mathrm{SO}_{2}$ and $\mathrm{H}_{2} \mathrm{O}$ can notably decrease the catalytic activity for both RMbased catalyst and commercial vanadium-based catalyst under GHSV at $60000 \mathrm{~h}^{-1}$ (Fig. 3a). The VWTi catalyst, without inactive additives as comparison, is also exhibited in Fig. S2B. $\dagger$ Notably, although the vanadium based catalyst has better denitration activity at a medium temperature range of 300-
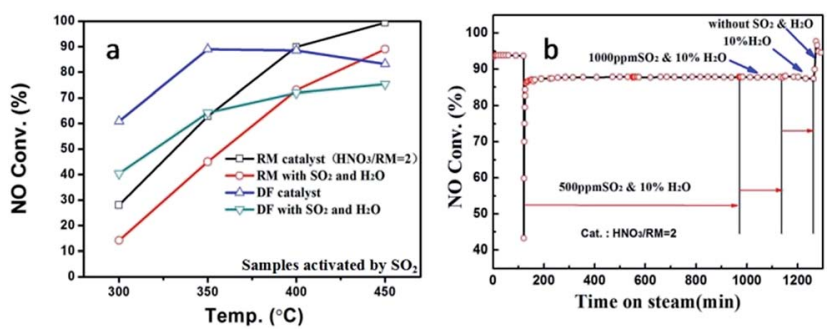

Fig. 3 The activity comparison between $\mathrm{SO}_{2}$-activated $\mathrm{RM}$ and commercial DF catalysts (a), and catalytic stability of RM catalysts with/ without $\mathrm{SO}_{2}$ and $\mathrm{H}_{2} \mathrm{O}$ at $450{ }^{\circ} \mathrm{C}$ (b). 
$350{ }^{\circ} \mathrm{C}$, the RM-based catalysts have comparable, or even high catalytic activity, at a high temperature range above $350{ }^{\circ} \mathrm{C}$. The results demonstrate the great advantage of a RM-based catalyst for its application in the denitration of high-temperature flue gas. Moreover, the stability of RM-based catalyst was further investigated in different gas compositions as shown in Fig. $3 \mathrm{~b}$ at the temperature of $450{ }^{\circ} \mathrm{C}$. After $500 \mathrm{ppm} \mathrm{SO}_{2}$ and $10 \% \mathrm{H}_{2} \mathrm{O}$ is introduced, the NO conversion reduces about ten percentage point, but can maintain stable catalytic activity even with 1000 ppm $\mathrm{SO}_{2}$ and $10 \% \mathrm{H}_{2} \mathrm{O}$. It is interesting that cutting off $\mathrm{SO}_{2}$ can't recover the catalytic activity, but simultaneously cutting off $\mathrm{H}_{2} \mathrm{O}$ will have the same NO removal efficiency as with the initial value. These results show that the catalytic activity of $\mathrm{RM}$ catalyst was mainly inhibited by $\mathrm{H}_{2} \mathrm{O}$ in the flue gas, which should be a result from the competitive adsorption of $\mathrm{H}_{2} \mathrm{O}$ on active sites. The demonstrated stability of the RM-based catalyst implies its promising application prospects for purification of real flue gas.

\subsection{Composition and structure of RM-based catalysts}

To better understand the above excellent denitration activity of the RM-based catalysts, their basic compositions and structures were studied and are reported in detail here. Table 1 shows XRF results of the different $\mathrm{RM}$ samples. In the original $\mathrm{RM}$, the main components are $\mathrm{Fe}_{2} \mathrm{O}_{3}$ (37.87 wt\%), $\mathrm{Al}_{2} \mathrm{O}_{3}$ (24.02 wt\%), $\mathrm{SiO}_{2}(16.65 \mathrm{wt} \%)$, and $\mathrm{TiO}_{2}$ (7.63 wt $\left.\%\right)$, which exactly constitute the active component (iron oxide) and supports a denitration catalyst. However, the original sample has very high $\mathrm{Na}_{2} \mathrm{O}$ content (11.16 wt\%) and other alkaline-earth metals, such as $\mathrm{CaO}$ and $\mathrm{MgO}$, which can severely poison and inactivate the denitration catalyst. Acid treatment of RM and the subsequent washing process dramatically decreases the alkali metal to a very low level. Increased washing times from none to thrice gradually decreased the alkali oxides contents, but the amount of alkaline earth oxides still maintained a high value after washing more than two times for the cases of $\mathrm{HNO}_{3} / \mathrm{RM}$ ratios at 0.5 and 1 . As the $\mathrm{HNO}_{3} / \mathrm{RM}$ ratio goes above 1 , the content of both of alkali oxides and alkaline earth oxides decreases greatly to a very low level. These results manifest that the alkali/ alkaline-earth metal elements can be removed to a limit with the $\mathrm{HNO}_{3} / \mathrm{RM}$ ratio exceeding 1 after washing above two times, which should eliminate the poisoning effect of alkali/alkaline-

Table 1 XRF results of the original and treated RM samples

\begin{tabular}{lcccccccc}
\hline Samples & $\mathrm{Fe}_{2} \mathrm{O}_{3}$ & $\mathrm{Al}_{2} \mathrm{O}_{3}$ & $\mathrm{SiO}_{2}$ & $\mathrm{TiO}_{2}$ & $\mathrm{Na}_{2} \mathrm{O}$ & $\mathrm{CaO}$ & $\mathrm{K}_{2} \mathrm{O}$ & $\mathrm{MgO}$ \\
\hline Original & 37.87 & 24.02 & 16.65 & 7.63 & 11.16 & 1.24 & 0.09 & 0.11 \\
Washed-none & 41.54 & 24.63 & 16.47 & 7.95 & 6.74 & 1.59 & 0.06 & 0.12 \\
Washed-once & 44.00 & 26.83 & 17.80 & 8.45 & 0.51 & 1.35 & 0.05 & 0.09 \\
Washed-twice & 44.97 & 25.69 & 18.13 & 8.82 & 0.36 & 0.97 & 0.04 & 0.09 \\
Washed-thrice & 44.98 & 25.99 & 17.97 & 8.70 & 0.36 & 0.97 & 0.05 & 0.08 \\
$\mathrm{HNO}_{3} / \mathrm{RM}=0.5$ & 44.72 & 26.36 & 17.29 & 8.51 & 0.60 & 0.99 & 0.18 & 0.10 \\
$\mathrm{HNO}_{3} / \mathrm{RM}=1$ & 44.98 & 25.99 & 17.97 & 8.70 & 0.36 & 0.97 & 0.05 & 0.08 \\
$\mathrm{HNO}_{3} / \mathrm{RM}=2$ & 44.96 & 26.02 & 16.07 & 7.75 & 0.13 & 0.35 & 0.04 & 0.07 \\
$\mathrm{HNO}_{3} / \mathrm{RM}=3$ & 44.42 & 25.51 & 16.10 & 7.79 & 0.12 & 0.36 & 0.04 & 0.10
\end{tabular}

reactions.

The XRD patterns in Fig. $\mathrm{S} 3 \uparrow$ demonstrate that all the $\mathrm{RM}$ samples have their main diffraction peaks at 24.2, 33.3, 35.8, $41.2,49.8,54.2,62.7$, and $64.2^{\circ}$ belonging to hematite $\left(\mathrm{Fe}_{2} \mathrm{O}_{3}\right)$ phase (JCPDS 33-0664). Anatase $\mathrm{TiO}_{2}$ can also be observed at 25.5 and $48.1^{\circ}$ according to JCPDS 21-1272. The original RM sample (Fig. S3a $\dagger$ ) has a notable diffraction peak at $14.0^{\circ}$, which can be assigned to zeolite-like sodium silicoaluminate (JCPDS 40-0101). After acid treatment without washing (Fig. S3b $\dagger$ ), the sodium salt is converted to albite sodium silicoaluminate at 28.1 (JCPDS 10-0393). And this peak disappeared after the washing process or increased $\mathrm{HNO}_{3} / \mathrm{RM}$ ratio (Fig. S3c- $\mathrm{f}_{\dagger}^{\dagger}$ ), indicating the cleaning of sodium element in RM samples after the acid treatment and washing process. Meanwhile, no silicon and aluminium oxide species are observed in the XRD patterns in Fig. $\mathrm{S} 3, \dagger$ indicating they are in the amorphous form. In addition, the increased calcination temperature will not cause an obvious change in RM samples (Fig. S3g and $h \dagger$ ). The shown structure transformation of different RM samples is well consistent with the composition change of XRF data in Table 1. In combination with the catalytic results in Fig. 1, it can be concluded that the elimination of alkaline elements by the acid treatment and washing process makes the RM waste active for $\mathrm{NH}_{3}$-SCR reactions.

The morphology features of these RM samples were characterized by SEM and TEM as shown in Fig. 4. In the case of the original RM sample, many bulky grains can be observed with a micron grade size (Fig. 4A and B). After the acid treatment and washing process, the particles of the RM samples become more dispersed in a nanoscale range of 50-800 nm (Fig. 4C). High resolution TEM can clearly observe the lattice fringe phase of $\alpha$ $\mathrm{Fe}_{2} \mathrm{O}_{3}$ (104) crystal face with the lattice distance of $0.27 \mathrm{~nm}$ (Fig. 4D), which is in accord with the XRD results in Fig. S3. $\dagger$ For a sufficiently $\mathrm{SO}_{2}$ activated sample, the particles become much smaller than the corresponding fresh sample (Fig. S3E $\dagger$ ). Moreover, the lattice fringe phase of $\mathrm{Fe}_{2}\left(\mathrm{SO}_{4}\right)_{3}$ (113) crystal face with a lattice distance of $0.36 \mathrm{~nm}$ is observed except with the $\alpha$ $\mathrm{Fe}_{2} \mathrm{O}_{3}$ phase, indicating the conversion of part $\alpha-\mathrm{Fe}_{2} \mathrm{O}_{3}$ to $\mathrm{Fe}_{2}\left(\mathrm{SO}_{4}\right)_{3}$ after the activation by $\mathrm{SO}_{2}$.

To have deep insight into the change of surface area and pore-size distribution after treatment, a BET test was performed. Fig. 5 displays the $\mathrm{N}_{2}$ adsorption-desorption isotherm and the corresponding pore size distribution curve for different RM samples. All the samples exhibit the typical IV isotherm with a H3-type hysteresis loop $\left(P / P_{0}>0.4\right)$, indicating the mesoporous characteristics of these RM-based catalysts (Fig. 5A). ${ }^{\mathbf{1 0}}$ In combination with the quantitative data summarized in Table 2, it can be found that the acid treatment and washing process has great impact on surface area and pore-size distribution. The surface area is as low as $26.8 \mathrm{~m}^{2} \mathrm{~g}^{-1}$ for the original RM. In contrast, the acid treatment and washing process can dramatically increase their surface area with a maximum of $134.1 \mathrm{~m}^{2} \mathrm{~g}^{-1}$ as the ratio of $\mathrm{HNO}_{3} / \mathrm{RM}$ increased to 2, which may derive from an increased dispersity of the amorphous silicon and aluminium oxide species. But the further elevated $\mathrm{HNO}_{3}$ / $\mathrm{RM}$ ratio to 3 inversely decreased the value of the surface area. 

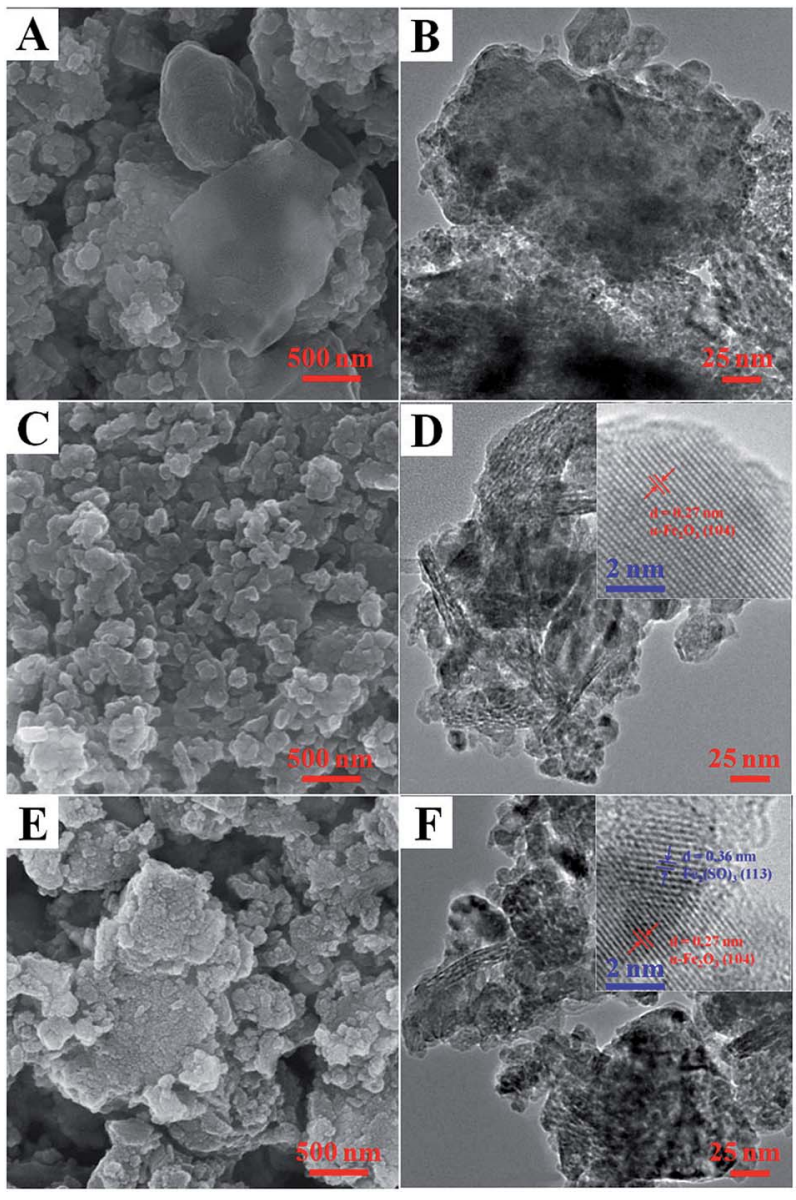

Fig. 4 SEM and TEM images of the original RM sample $(A, B)$, the typical fresh RM catalyst (C, D), and the $\mathrm{SO}_{2}$-activated RM catalyst $(E, F)$ together with their high resolution TEM images (the insert).
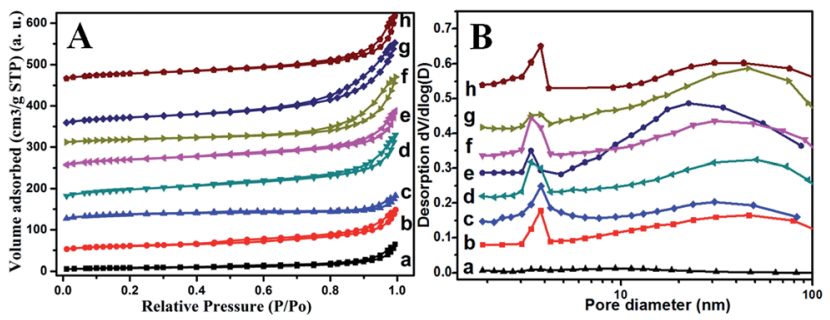

Fig. 5 The $\mathrm{N}_{2}$ adsorption-desorption isotherms curves (A) and the corresponding pore size distributions calculated from the desorption branch of the RM-based samples (B): (a) the original sample, (b) the sample of $\mathrm{HNO}_{3} / \mathrm{RM}=0.5$, (c) the sample of $\mathrm{HNO}_{3} / \mathrm{RM}=1$ without washing, (d) the sample of $\mathrm{HNO}_{3} / \mathrm{RM}=1$ washed twice, (e) the sample of $\mathrm{HNO}_{3} / \mathrm{RM}=2$, (f) the activated sample of $(\mathrm{e}, \mathrm{g})$ calcination of (e) at $600{ }^{\circ} \mathrm{C}$, and (h) the sample of $\mathrm{HNO}_{3} / \mathrm{RM}=3$.

Moreover, elevating the calcination temperature to $600{ }^{\circ} \mathrm{C}$ decreased the BET area owing to the sintering of RM particles. The mesoporous features are shown in Fig. 5B. The original RM has few pores with a very small pore volume $\left(0.09 \mathrm{~cm}^{2} \mathrm{~g}^{-1}\right)$. The acid treatment and washing process results in a pore distribution between 1 and $10 \mathrm{~nm}$ and $10-100 \mathrm{~nm}$ with obviously increased pore volume. Similarly, with the change of BET area,
Table 2 Summary BET data of the RM-based samples

\begin{tabular}{llll}
\hline Samples & $\begin{array}{l}\text { BET surface } \\
\text { areas }\left(\mathrm{m}^{2} \mathrm{~g}^{-1}\right)\end{array}$ & $\begin{array}{l}\text { Pore volume } \\
\left(\mathrm{cm}^{3} \mathrm{~g}^{-1}\right)\end{array}$ & $\begin{array}{l}\text { Pore size } \\
(\mathrm{nm})\end{array}$ \\
\hline Original & 26.8 & 0.09 & 19.5 \\
$\mathrm{HNO}_{3} / \mathrm{RM}=0.5$ & 69.5 & 0.14 & 10.6 \\
$\mathrm{HNO}_{3} / \mathrm{RM}=1$, washed-none & 65.2 & 0.16 & 13.3 \\
$\mathrm{HNO}_{3} / \mathrm{RM}=1$, washed-twice & 113.8 & 0.23 & 17.5 \\
$\mathrm{HNO}_{3} / \mathrm{RM}=2$ & 134.1 & 0.32 & 9.6 \\
$\mathrm{HNO}_{3} / \mathrm{RM}=2,600{ }^{\circ} \mathrm{C}$ & 106.3 & 0.22 & 9.8 \\
$\mathrm{HNO}_{3} / \mathrm{RM}=2, \mathrm{SO}_{2}$ activated & 127.2 & 0.20 & 10.4 \\
$\mathrm{HNO}_{3} / \mathrm{RM}=3$ & 101.1 & 0.25 & 12.6
\end{tabular}

the pore volume increases to its maximum value $\left(0.32 \mathrm{~cm}^{2} \mathrm{~g}^{-1}\right)$ at a $\mathrm{HNO}_{3} / \mathrm{RM}$ ratio of 2 and then decreases. The increased calcination temperature at $600{ }^{\circ} \mathrm{C}$ also decreases the pore volume but the washing process can remarkably increase it.

As shown by the above XRF and XRD results, the original RM sample is mainly composed of $\mathrm{Fe}_{2} \mathrm{O}_{3}, \mathrm{TiO}_{2}$, and aluminum silicate sodium. The added $\mathrm{HNO}_{3}$ can dissolve part of the $\mathrm{Fe}_{2} \mathrm{O}_{3}$ and aluminum silicate sodium, and the subsequent neutral reaction by $\mathrm{NaOH}$ forms a colloidal turbid liquid as observed during the preparation process. The colloidal turbid liquid may contain ferric hydroxide, alumina/silica sol, and undissolved $\mathrm{TiO}_{2}$ and other RM components. Meanwhile, alkali/alkalineearth metal elements are released and eliminated by the washing process. The RM-based catalysts are obtained by drying the colloidal turbid liquid and following the calcination process. Based on the physicochemical change during the preparation process, the increased BET area and abundant pore structure of RM-based catalysts can be attributed to dissolution and precipitation of RM constituents during the acid-alkali treatment process. On the other hand, the release of sodium element from aluminum silicate salt may also contribute to increasing the surface area and enriching the pore structure. But too much $\mathrm{HNO}_{3}$ may destroy the skeletal aluminum silicate structure, resulting in the decreased BET area and pore volume. The calcination at high temperature enhances the agglomeration of RM particles and also decreases the surface area and pore volume. Most notably, the catalytic activity in Fig. 2 is highly relevant to the BET area of RM samples listed in Table 2, revealing that the dispersion of RM particles is another key factor to determine their catalytic activity. For a $\mathrm{SO}_{2}$ activated sample, although it has a slightly decreased BET area and pore structure compared with its fresh sample, its activity still improved significantly as shown in Fig. 2D. The reason will be discussed in the following text.

For a better understanding of the significant promotion effect of $\mathrm{SO}_{2}$ activation on the catalytic performance of RMbased catalysts, detailed structures of the activated catalysts were studied by TG, XRD, and XPS analysis. For the TG results in Fig. 6A, the fresh RM sample has no weight lost above $200{ }^{\circ} \mathrm{C}$. But the $\mathrm{SO}_{2}$ activated catalyst shows $7.6 \mathrm{wt} \%$ weight lost between $550{ }^{\circ} \mathrm{C}$ and $700{ }^{\circ} \mathrm{C}$, which can be assigned to be the decomposition of $\mathrm{Fe}_{2}\left(\mathrm{SO}_{4}\right)_{3}$ in contrast with the TG curve of pure $\mathrm{Fe}_{2}\left(\mathrm{SO}_{4}\right)_{3}$. Correspondingly, its XRD patterns show an extra small peak at $24.8^{\circ}$ compared with the fresh one (Fig. 6B), which 

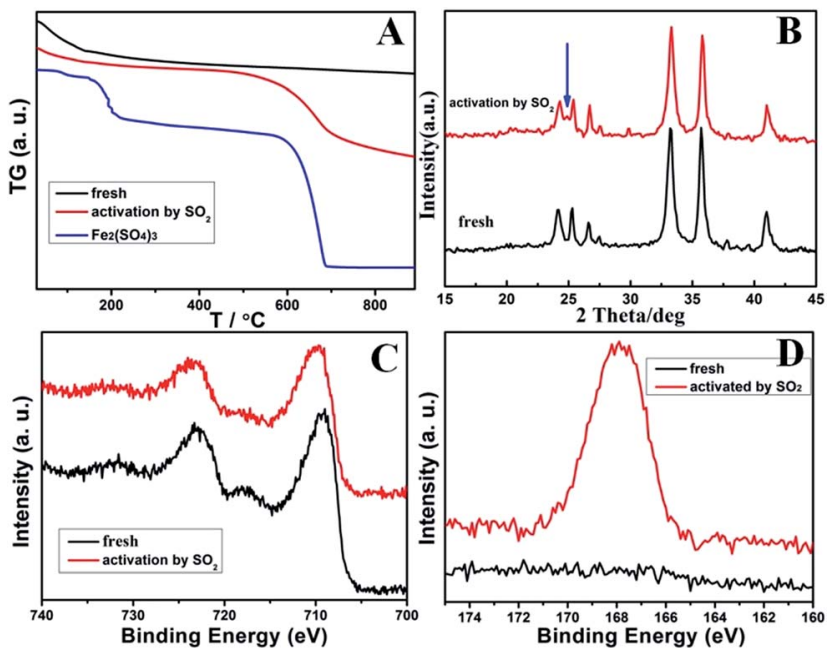

Fig. 6 The TG (A), XRD (B), Fe $2 p$ XPS (C) together with the S $2 p$ XPS (D) data of the fresh and $\mathrm{SO}_{2}$-activated RM catalysts.

can be assigned to the $\mathrm{Fe}_{2}\left(\mathrm{SO}_{4}\right)_{3}$. These results are quite consistent with the lattice fringe phase of $\mathrm{Fe}_{2}\left(\mathrm{SO}_{4}\right)_{3}$ observed by HRTEM. These evidences readily confirm the formation of an $\mathrm{Fe}_{2}\left(\mathrm{SO}_{4}\right)_{3}$ phase on the surface of RM-based catalysts after activation by $\mathrm{SO}_{2}$. Moreover, the formation of $\mathrm{Fe}_{2}\left(\mathrm{SO}_{4}\right)_{3}$ also changes the XPS signals as shown for Fe $2 \mathrm{P}$ and $\mathrm{S} 2 \mathrm{p}$ spectrogram in Fig. $5 \mathrm{C}$ and $\mathrm{D}$. Fresh $\mathrm{RM}$ catalyst exhibits the Fe $2 \mathrm{p}_{1 / 2}$ and $2 \mathrm{p}_{3 / 2}$ signals at $712.5 \mathrm{eV}$ and $724.8 \mathrm{eV}$, respectively, which can be assigned to $\mathrm{Fe}_{2} \mathrm{O}_{3}{ }^{11}$ The corresponding $\mathrm{Fe} 2 \mathrm{p}$ peak for the $\mathrm{SO}_{2}$ activated catalyst obviously moves towards high binding energy about $0.2 \mathrm{eV}$, owing to the more polarized electron feature in $\mathrm{Fe}_{2}\left(\mathrm{SO}_{4}\right)_{3}$ than $\mathrm{Fe}_{2} \mathrm{O}_{3}$. Compared with the fresh sample, a strong S 2p XPS signal is detected for a $\mathrm{SO}_{2}$ activated RM sample, which can also evidence the existence of sulfate species. In consideration of the significantly increased catalytic activity for the $\mathrm{SO}_{2}$ activated $\mathrm{RM}$ catalyst in Fig. 2 and some literature reports, ${ }^{12}$ the generated $\mathrm{Fe}_{2}\left(\mathrm{SO}_{4}\right)_{3}$ species may form new active sites in the $\mathrm{RM}$ catalyst for the $\mathrm{NH}_{3}$-SCR reaction.

In brief, it can be concluded that the clearing of alkali/ alkaline-earth metal elements in the original RM sample by the ball milling and acid-base neutralization method can eliminate their poisoning effect and thus makes the RM waste active for the denitration reaction. Meanwhile, increased particle dispersion and BET area of RM by a proper $\mathrm{HNO}_{3} / \mathrm{RM}$ ratio and calcination temperature can improve their catalytic activity by exposing more active sites. In addition, formation of $\mathrm{Fe}_{2}\left(\mathrm{SO}_{4}\right)_{3}$ for the $\mathrm{SO}_{2}$-activated catalyst will serve as a new active species and further enhance its denitration activity.

\subsection{Adsorption/reaction features of catalytic active sites}

3.3.1 The $\mathbf{H}_{2}$-TPR and $\mathrm{NH}_{3}$-TPD study. The results of $\mathrm{H}_{2}$ temperature programmed reduction $\left(\mathrm{H}_{2}\right.$-TPR) over three $\mathrm{RM}$ based catalysts (washed-none, washed-thrice and activated by $\mathrm{SO}_{2}$ ) are given in Fig. 7. Two reduction peaks are observed at around $400{ }^{\circ} \mathrm{C}$ and $650{ }^{\circ} \mathrm{C}$, which can be assigned to reduction of the $\mathrm{Fe}_{2} \mathrm{O}_{3}$ species to $\mathrm{FeO}$ and $\mathrm{Fe}$, respectively. ${ }^{8,13,14}$ For the

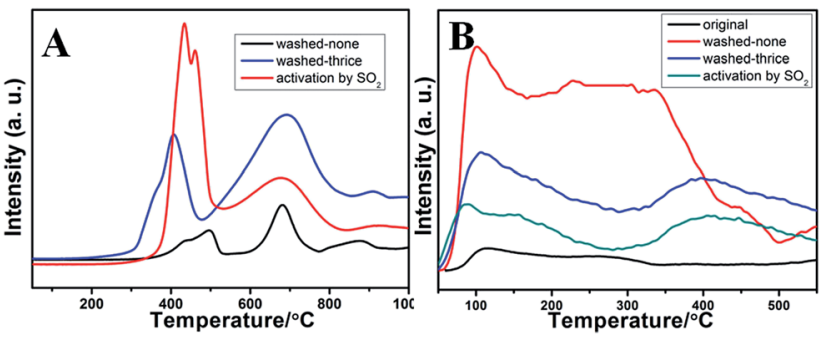

Fig. 7 The $\mathrm{H}_{2}$-TPR (A) and $\mathrm{NH}_{3}-\mathrm{TPD}$ (B) curves for the RM-based samples.

sample activated by $\mathrm{SO}_{2}$, the shoulder peak $\left(463{ }^{\circ} \mathrm{C}\right)$ close to the main peak $\left(430^{\circ} \mathrm{C}\right)$ may be assigned to the reduction of iron sulfate species on the surface of the catalyst observed in Fig. 7. Compared with the washed-none sample, the significantly increased peak area shows more $\mathrm{Fe}_{2} \mathrm{O}_{3}$ species can be reduced for the washed-thrice sample, which may be due to its decreased content of alkali metal. After being activated by $\mathrm{SO}_{2}$, the peak area at the low-temperature range obviously increases, indicating easy reducibility for the generated ferric sulfate species. For Fe-based catalysts, the valence change of $\mathrm{Fe}^{3+} / \mathrm{Fe}^{2+}$ plays a key role in the $\mathrm{NH}_{3}$ SCR reaction, and more reducible ferric oxide species always have more active sites with high catalytic activity. ${ }^{7,14}$ In our cases, more reducible $\mathrm{Fe}_{2} \mathrm{O}_{3}$ species between 350-500 ${ }^{\circ} \mathrm{C}$ for washed-thrice and $\mathrm{SO}_{2}$-activated samples mean the exposure of more active iron sites for the $\mathrm{NH}_{3}$ SCR reaction in the high-temperature region, which may be relevant with the observed enhanced activity in Fig. 2.

Temperature programmed desorption of ammonia $\left(\mathrm{NH}_{3}-\right.$ TPD) experiments were further carried out to evaluate the acidity of RM-based catalysts as shown in Fig. 7B. It can be seen that the adsorption capacity of $\mathrm{NH}_{3}$ increases significantly for the treated RM sample compared with the original one, which may result from the strong active acid sites on the surface of amorphous silicon and aluminum oxides after acid treatment. All the three samples (washed-none, washed-thrice, and $\mathrm{SO}_{2}$ activated) exhibit the $\mathrm{NH}_{3}$ desorption peaks at $100{ }^{\circ} \mathrm{C}$ and $380{ }^{\circ} \mathrm{C}$, respectively. For the washed-thrice sample, the $\mathrm{NH}_{3}$ adsorption capacity obviously increases compared with the washed-none sample owing to the elimination of alkaline elements. Moreover, $\mathrm{NH}_{3}$ adsorption capacity of the $\mathrm{SO}_{2}$ activated sample increases dramatically for both the low and high temperature peaks, indicating increased acidity derived from the generation of ferric sulfate species. As the main reaction molecule, the $\mathrm{NH}_{3}$ desorption features will have great impact on their catalytic behavior as discussed in the following text.

3.3.2 The reaction mechanism study by in situ IR. For better understanding properties of active sites, the adsorption and reaction process were studied by an in situ IR method over an $\mathrm{HNO}_{3} / \mathrm{RM}=2$ sample, and the results are shown in Fig. 8. For $\mathrm{NH}_{3}$ desorption from $30-400{ }^{\circ} \mathrm{C}$ (Fig. 8A), the peak around $1440 \mathrm{~cm}^{-1}$, can be ascribed to $\mathrm{NH}_{4}{ }^{+}$species on Brønsted acid sites. ${ }^{15}$ Meanwhile, little peaks assigned to Lewis acid sites (such as $\sim 1600 \mathrm{~cm}^{-1}$ and $1220 \mathrm{~cm}^{-1}$ ) can be observed. ${ }^{16}$ These results reveal that the RM-based catalysts contain mainly 

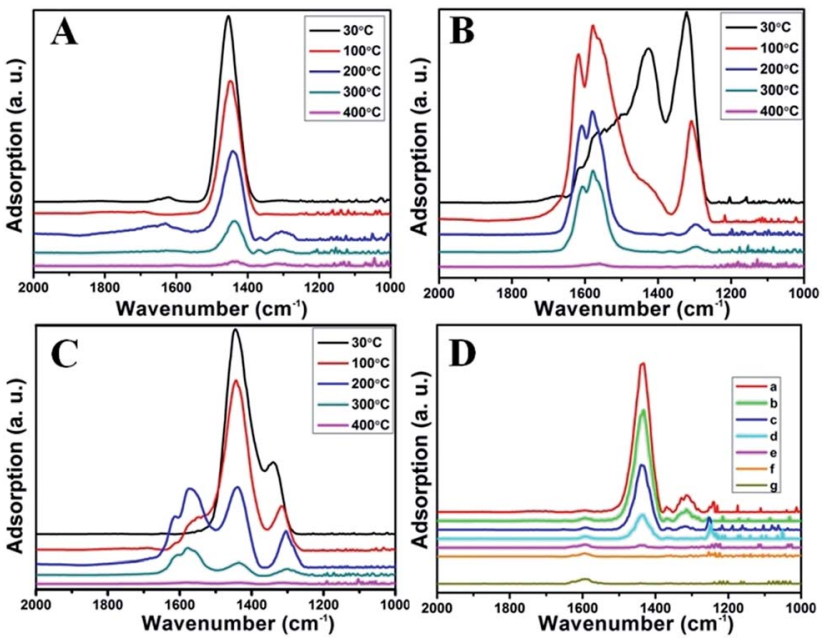

Fig. 8 The in situ IR results for $\mathrm{NH}_{3}$ desorption (A), $\mathrm{NO}$ desorption (B) and co-desorption of $\mathrm{NH}_{3}$ and $\mathrm{NO}$ at different temperature (C); the reaction process for $\mathrm{NH}_{3}-\mathrm{SCR}$ at $350^{\circ} \mathrm{C}$ (D): (a-f) the time-dependent changes of absorbed $\mathrm{NH}_{3}$ in a flow of $\mathrm{NO}+\mathrm{O}_{2}$ for 0 min, 1 min, 2 min, $3 \mathrm{~min}, 4 \mathrm{~min}$, and $5 \mathrm{~min}$, respectively, (g) the adsorption of $\mathrm{NO}+\mathrm{O}_{2}$.

Brønsted acid sites. As the temperature elevates from 30 to $400{ }^{\circ} \mathrm{C}$, the peak at $1440 \mathrm{~cm}^{-1}$ becomes weak gradually with the desorption of $\mathrm{NH}_{3}$ adsorbed at Brønsted acid sites. At $400{ }^{\circ} \mathrm{C}$, only a very weak peak at $1440 \mathrm{~cm}^{-1}$ indicated the desorption of most of the adsorbed $\mathrm{NH}_{3}$ at this temperature, which is in accordance with the high-temperature desorption peak at $\sim 400{ }^{\circ} \mathrm{C}$ as shown in $\mathrm{NH}_{3}$-TPD results in Fig. 7B.

Fig. 8B illustrates the DRIFT desorption spectra of $\mathrm{NO}+\mathrm{O}_{2}$ on the RM catalyst at different temperatures. Several distinct peaks appear at 1610, 1580, 1555, 1425, and $1322 \mathrm{~cm}^{-1}$, which can be ascribed to adsorbed $\mathrm{NO}_{2}\left(1610 \mathrm{~cm}^{-1}\right)$, bidentate nitrate $\left(1580 \mathrm{~cm}^{-1}\right)$, monodentate nitrate $\left(1554 \mathrm{~cm}^{-1}\right)$, linear nitrate $\left(1425 \mathrm{~cm}^{-1}\right)$, and $\mathrm{M}-\mathrm{NO}_{2}$ nitro species $\left(1322 \mathrm{~cm}^{-1}\right)$, respectively. ${ }^{17-20}$ From 30 to $100{ }^{\circ} \mathrm{C}$, the linear nitrate $\left(1425 \mathrm{~cm}^{-1}\right)$ and $\mathrm{M}-\mathrm{NO}_{2}\left(1322 \mathrm{~cm}^{-1}\right)$ get weak together with the increase of strongly adsorbed $\mathrm{NO}_{2}\left(1610 \mathrm{~cm}^{-1}\right)$ and bidentate nitrate $\left(1580 \mathrm{~cm}^{-1}\right)$. These results imply the easy oxidation of $\mathrm{NO}$ by $\mathrm{O}_{2}$ to $\mathrm{NO}_{2}$ on $\mathrm{RM}$ catalyst at low temperatures, which is a key step for the "fast SCR" reaction. ${ }^{21}$ As the temperature increased, the $\mathrm{NO}_{2}\left(1610 \mathrm{~cm}^{-1}\right)$ and bidentate nitrate $\left(1580 \mathrm{~cm}^{-1}\right)$ were rapidly desorbed and little adsorbed species are observed at $400{ }^{\circ} \mathrm{C}$.

Fig. 8C shows the co-desorption curves of $\mathrm{NH}_{3}$ and $\mathrm{NO}+\mathrm{O}_{2}$ over the RM catalyst at different temperatures. Compared with the independent desorption of $\mathrm{NH}_{3}$ and $\mathrm{NO}+\mathrm{O}_{2}$, the adsorbed $\mathrm{NO}_{2}\left(1610 \mathrm{~cm}^{-1}\right)$ decreased dramatically from 30 to $300{ }^{\circ} \mathrm{C}$, indicating the reaction of adsorbed $\mathrm{NO}_{2}$ and $\mathrm{NH}_{3}$ species through a "fast SCR" route to reduce the generated $\mathrm{NO}_{2} \cdot{ }^{21-23}$ However, the surface species of bidentate nitrate $\left(1580 \mathrm{~cm}^{-1}\right)$ from absorbed $\mathrm{NO}$ and $\mathrm{NH}_{4}{ }^{+}\left(1440 \mathrm{~cm}^{-1}\right)$ from absorbed $\mathrm{NH}_{3}$ simultaneously exist on the RM catalyst from 200 to $300{ }^{\circ} \mathrm{C}$. Generally, the $\mathrm{NH}_{3}$ SCR may follow a Langmuir-Hinshelwood or Eley-Rideal mechanism as follows, in which $\mathbf{M}$ is the metal active site. ${ }^{\mathbf{6} 24-26}$ Based on the Langmuir-Hinshelwood mechanism, the results clearly reveal that the RM catalysts are very inactive for a $\mathrm{NH}_{3}$-SCR reaction through the Langmuir-Hinshelwood mechanism at relatively low temperatures $\left(<300{ }^{\circ} \mathrm{C}\right)$. In combination with the TPR results in Fig. 7A, the low activity may be due to the difficult conversion for $\mathrm{Fe}^{3+} / \mathrm{Fe}^{2+}$ active sites below $300{ }^{\circ} \mathrm{C}$. The further increase of temperature to $400{ }^{\circ} \mathrm{C}$ removed all the absorbed species by desorption or interreaction.

The Langmuir-Hinshelwood mechanism:

$$
\begin{gathered}
\mathrm{NH}_{3}(\mathrm{~g}) \stackrel{\mathrm{M}}{\longrightarrow} \mathrm{NH}_{3}(\mathrm{ad}) \\
\mathrm{NH}_{3}(\mathrm{ad}) \stackrel{\mathrm{M}}{\longrightarrow} \mathrm{NH}_{2}(\mathrm{ad})+\mathrm{H}(\mathrm{ad}) \\
\mathrm{NO}(\mathrm{g}) \stackrel{\mathrm{M}}{\longrightarrow} \mathrm{NO}(\mathrm{ad}) \\
\mathrm{NO}(\mathrm{ad})+\mathrm{O}^{2-}(\mathrm{s}) \stackrel{\mathrm{M}}{\longrightarrow} \mathrm{NO}_{2}^{-}(\mathrm{ad}) \\
\mathrm{NO}_{2}{ }^{-}(\mathrm{ad})+\mathrm{NH}_{3}(\mathrm{ad}) \stackrel{\mathrm{M}}{\longrightarrow} \mathrm{N}_{2}(\mathrm{~g})+\mathrm{H}_{2} \mathrm{O}(\mathrm{g})+\mathrm{OH}^{-}(\mathrm{ad}) \\
1 / 2 \mathrm{O}_{2}(\mathrm{~g}) \stackrel{\mathrm{M}}{\longrightarrow} \mathrm{O}^{2-}(\mathrm{s})
\end{gathered}
$$

The Eley-Rideal mechanism:

$$
\begin{gathered}
\mathrm{NH}_{3}(\mathrm{~g}) \stackrel{\mathrm{M}}{\longrightarrow} \mathrm{NH}_{3}(\mathrm{ad}) \\
\mathrm{NH}_{3}(\mathrm{ad}) \stackrel{\mathrm{M}}{\longrightarrow} \mathrm{NH}_{2}(\mathrm{ad})+\mathrm{H}(\mathrm{ad}) \\
\mathrm{NH}_{2}(\mathrm{ad})+\mathrm{NO}(\mathrm{g}) \stackrel{\mathrm{M}}{\longrightarrow} \mathrm{NH}_{2} \mathrm{NO}(\mathrm{ad}) \rightarrow \mathrm{N}_{2}(\mathrm{~g})+\mathrm{H}_{2} \mathrm{O}(\mathrm{g}) \\
1 / 2 \mathrm{O}_{2}(\mathrm{~g}) \stackrel{\mathrm{M}}{\longrightarrow} \mathrm{O}^{2-}(\mathrm{s})
\end{gathered}
$$

To further make clear the reaction mechanism of RM-based catalysts at high temperature, more DRIFT spectra were collected to observe the reaction details at $350{ }^{\circ} \mathrm{C}$ in Fig. 8D. The relatively high temperature of $350{ }^{\circ} \mathrm{C}$ was chosen to avoid the interference of low signal to noise ratio owing to the weak absorbed signal at a high temperature. Fig. $8 D(a-f)$ presents the time-dependent changes of the in situ DRIFT spectra of the RM catalyst in a flow of $\mathrm{NO}$ and $\mathrm{O}_{2}$ after the catalyst was pre-exposed to a flow of $\mathrm{NH}_{3}$ at $350{ }^{\circ} \mathrm{C}$. A strong peak assigned to absorbed $\mathrm{NH}_{4}{ }^{+}$can be clearly seen at $1440 \mathrm{~cm}^{-1}$ after being pre-exposed to a flow of $\mathrm{NH}_{3}$ at $350{ }^{\circ} \mathrm{C}$ (Fig. $8 \mathrm{D}(\mathrm{a})$ ). Notably, the absorbed $\mathrm{NH}_{4}{ }^{+}$ disappeared gradually but very fast (within $5 \mathrm{~min}$ ) after the introduction of $\mathrm{NO}+\mathrm{O}_{2}$ over the $\mathrm{NH}_{3}$ pre-exposed catalyst (from Fig. $8 \mathrm{D}(\mathrm{b}-\mathrm{f}))$, which shows the fast reaction rate between absorbed $\mathrm{NH}_{4}{ }^{+}$and the introduced $\mathrm{NO}+\mathrm{O}_{2}$. On the other hand, little surface species can be observed after pre-exposure of the 
catalyst over $\mathrm{NO}+\mathrm{O}_{2}$ flow at $350{ }^{\circ} \mathrm{C}$ (Fig. $8 \mathrm{D}(\mathrm{g})$ ), suggesting a very weak absorption of NO on the catalytic surface at $350{ }^{\circ} \mathrm{C}$. According to the Eley-Rideal mechanism, $\mathrm{NH}_{3}$ is first absorbed on the acid sites and then reacts with the gaseous NO. These comparative results clearly demonstrate that the $\mathrm{NH}_{3}$-SCR reaction over $\mathrm{RM}$ catalyst follows the Eley-Rideal reaction mechanism above $350{ }^{\circ} \mathrm{C}$, whose reaction scheme is shown in Scheme $\mathrm{S} 1 . \dagger$ In the reaction mechanism, $\mathrm{NH}_{3}$ is absorbed to form $\mathrm{NH}_{4}^{+}$species on acid sites, then interact with the $\mathrm{Fe}^{3+}$ based redox sites, and further capture gaseous NO to generate $\mathrm{N}_{2}$ and $\mathrm{H}_{2} \mathrm{O}$. Meanwhile, the $\mathrm{Fe}^{3+}$ species is converted to its $\mathrm{Fe}^{2+}$ state and then recovered by reaction with gaseous $\mathrm{O}_{2}$ to finish the catalytic cycle. Moreover, it can be seen that absorption of $\mathrm{NH}_{3}$ and conversion between $\mathrm{Fe}^{3+}$ and $\mathrm{Fe}^{2+}$ will play the key role in catalytic efficiency at high temperatures.

In brief, both $\mathrm{NH}_{3}$ and NO have strong absorption on the RM catalytic surface below $300{ }^{\circ} \mathrm{C}$. The difficult conversion for $\mathrm{Fe}^{3+} /$ $\mathrm{Fe}^{2+}$ at low temperatures may prevent the reaction of coabsorption $\mathrm{NH}_{3}$ and NO species following the Langmuir-Hinshelwood mechanism, but the $\mathrm{NH}_{3}$-SCR may still react slowly through the "fast SCR" route owing to the generation of absorbed $\mathrm{NO}_{2}$. But at the high temperature of $350{ }^{\circ} \mathrm{C}$, only $\mathrm{NH}_{3}$ species (but not NO) are absorbed on the catalytic surface and react with gaseous $\mathrm{NO}$ and $\mathrm{O}_{2}$, confirming that the hightemperature SCR reaction follows the Eley-Rideal mechanism over RM catalysts. The absorbed $\mathrm{NH}_{3}$ plays a key role in the Eley-Rideal mechanism. The high catalytic activity for RM catalyst at high temperatures is due to the strong and abundant acid sites together with the easy conversion for $\mathrm{Fe}^{3+} / \mathrm{Fe}^{2+}$ active sites on the catalytic surface.

\section{Conclusions}

In summary, this work demonstrates the successful reusage of $\mathrm{RM}$ waste as effective catalysts for a high-temperature $\mathrm{NH}_{3}$-SCR reaction by the ball milling and acid-base neutralization method, whose activity can further be enhanced by $\mathrm{SO}_{2}$ activation. The resulting RM-based catalysts have comparable catalytic activity and stability with the commercial V-W-Ti catalyst above $350{ }^{\circ} \mathrm{C}$ in the presence of $\mathrm{SO}_{2}$ and $\mathrm{H}_{2} \mathrm{O}$. Structure characterization data (XRF, XRD, SEM, TEM, BET, XPS, TG, and $\mathrm{H}_{2}$ TPR) reveal that the eliminated poisonous alkaline metal elements together with the increased dispersion of RM particles make RM waste active for a denitration reaction, and the formation of ferric sulfate species with more reducible $\mathrm{Fe}^{3+} / \mathrm{Fe}^{2+}$ active sites by the $\mathrm{SO}_{2}$ activation process can further enhance their denitration activity. The study by $\mathrm{NH}_{3}$-TPD and in situ IR further demonstrates that the $\mathrm{NH}_{3}$-SCR reaction over the RMbased catalyst follows the Eley-Rideal mechanism at high temperatures and the absorption of $\mathrm{NH}_{3}$ plays a key role in catalytic performance. The elimination of alkaline metal elements and $\mathrm{SO}_{2}$ activation process increases the absorption of $\mathrm{NH}_{3}$ and thus the DeNO${ }_{x}$ activity. The demonstrated reusage of $\mathrm{RM}$ waste as effective $\mathrm{DeNO}_{x}$ catalysts in this work will possess great application prospects for both resource utilization of RM waste and development of low cost $\mathrm{DeNO}_{x}$ catalysts.

\section{Conflicts of interest}

There are no conflicts to declare.

\section{Acknowledgements}

The authors are grateful for the financial support of Science and Technology Service Network Initiative of China (KFJ-SW-STS149), International Science and Technology Cooperation Program of China (2016YFE0128300), Natural Science and Foundation of China (Grant 21601192) and Postdoctoral Fellowship of Japan Society for the Promotion of Science (JSPS by $\mathrm{P} 15758)$.

\section{Notes and references}

1 H. Chen, G. Wang, Y. Xu, Z. Chen and F. Yin, RSC Adv., 2016, 6, 54202-54214.

2 J. Li, L. Xu, P. Sun, P. Zhai, X. Chen, H. Zhang, Z. Zhang and W. Zhu, Chem. Eng. J., 2017, 321, 622-634.

3 Y. Huang, W. Chai, G. Han, W. Wang, S. Yang and J. Liu, J. Hazard. Mater., 2016, 307, 318-327.

4 Z. P. Hu, H. Zhao, Z. M. Gao and Z. Y. Yuan, RSC Adv., 2016, 6, 94748-94755.

5 R. Li, T. Zhang, Y. Liu, G. Lv and L. Xie, J. Hazard. Mater., 2016, 316, 94-101.

6 M. Jablonska and R. Palkovits, Catal. Sci. Technol., 2016, 6, 49-72.

7 S. Yang, J. Li, C. Wang, J. Chen, L. Ma, H. Chang, L. Chen, Y. peng and N. Yan, Appl. Catal., B, 2012, 117-118, 73-80.

8 B. Li, Z. Huang, X. Huang, S. Kou, F. Liu, X. Zhang and H. Yang, RSC Adv., 2016, 6, 6300-6307.

9 W. Gu, M. Zhou, W. Ma and Y. Wang, Chem. Ind. Eng. Prog., 2012, 31, 1493-1500.

10 S. Li, H. Wang, W. Li, X. Wu, W. Tang and Y. Chen, Appl. Catal., B, 2015, 166-167, 260-269.

11 M. Casanova, L. Nodari, A. Sagar, K. Schermanz and A. Trovarelli, Appl. Catal., B, 2015, 176-177, 699-708.

12 L. Ma, J. Li, R. Ke and L. Fu, J. Phys. Chem. C, 2011, 115, 76037612 .

13 G. Wu, J. Li, Z. Fang, L. Lan, R. Wang, T. Lin, M. Gong and Y. Chen, Chem. Eng. J., 2015, 271, 1-13.

14 S. Yang, C. Liu, H. Chang, L. Ma, Z. Qu, N. Yan, C. Wang and J. Li, Ind. Eng. Chem. Res., 2013, 52, 5601-5610.

15 L. Lietti, J. L. Alemany, P. Forzatti, G. Busca, G. Ramis, E. Giamello and F. Bregani, Catal. Today, 1996, 29, 143-148.

16 Z. Liu, Y. Liu, B. Chen, T. Zhu and L. Ma, Catal. Sci. Technol., 2016, 6, 6688-6696.

17 L. Chen, J. Li and M. Ge, Environ. Sci. Technol., 2010, 44, 9590-9596.

18 M. Machida, M. Uto, D. Kurogi and T. Kijima, Chem. Mater., 2000, 12, 3158-3164.

19 F. Liu, H. He, Y. Ding and C. Zhang, Appl. Catal., B, 2009, 93, 194-204.

20 C. N. Costa and A. M. Efstathiou, J. Phys. Chem. B, 2004, 108, 2620-2630.

21 M. Iwasaki and H. Shinjoh, Appl. Catal., A, 2010, 390, 71-77. 
22 T. Du, H. Qu, Q. Liu, Q. Zhong and W. Ma, Chem. Eng. J., 2015, 262, 1199-1207.

23 X. Shi, F. Liu, L. Xie, W. Shan and H. He, Environ. Sci. Technol., 2013, 47, 3293-3298.

24 X. Lei, L. Wang, X. Zhao, Z. Chang, M. Jiang, D. Yan and X. Sun, Ind. Eng. Chem. Res., 2013, 52, 17934-17940.
25 B. Thirupathi and P. G. Smirniotis, Appl. Catal., B, 2011, 110, 195-206.

26 G. Busca, L. Lietti, G. Ramis and F. Berti, $R S C$ Adv., 2017, 7, 26226-26242. 